\title{
Comparison of Clonidine with Fentanyl as an Adjuvant to Isobaric Ropivacaine in Patients undergoing Vaginal Hysterectomy under Subarachnoid Block
}

\author{
Garima Choudhary ${ }^{1}$, Kriti Chaudhary ${ }^{2 *}$, Rajat Swami ${ }^{3}$, Rakesh Karnawat ${ }^{4}$ \\ ${ }^{1,2}$ AIIMS, Jodhpur, ${ }^{3,4}$ S N Medical College, Jodhpur
}

\begin{abstract}
Background
The use of adjuncts to local anaesthetics improves the standard of subarachnoid block (SAB). We compared intrathecal clonidine-ropivacaine combination and fentanyl-ropivacaine combination with respect to quality and duration of sensory/motor block and associated side effects.
\end{abstract}

\begin{abstract}
Subjects and methods
80 patients undergoing elective vaginal hysterectomy under SAB were enrolled for this hospital-based, prospective, randomized, double-blind study and divided into two groups of 40 each. As an adjuvant to $0.75 \%$ isobaric ropivacaine Group C received $75 \mu \mathrm{g}$ intrathecal clonidine $(0.5 \mathrm{ml})$ while Group $\mathrm{F}$ was given $25 \mu \mathrm{g}$ intrathecal fentanyl $(0.5 \mathrm{ml})$. The characteristics of sensory and motor block, duration of analgesia, intraoperative and postoperative Campbell sedation score, haemodynamic profile and any adverse event were recorded and analysed. Fischer exact or Chi-square test was used for the comparison of categorical data and unpaired t-test to compare the quantitative data using Statistical Packages for Social Sciences (SPSS) version 21. P value of $<0.05$ was considered statistically significant.
\end{abstract}

\section{Results}

Sensory and motor block duration, duration of analgesia, intraoperative and postoperative sedation score was significantly higher in Group C $(\mathrm{P}<0.05)$. Systolic blood pressure, diastolic blood pressure and mean blood pressure were significantly lower in Group $\mathrm{C}$ as compared to Group $\mathrm{F}$ at various time points with a similar overall incidence of hypotension from the baseline value.

\section{Conclusion}

Clonidine-ropivacaine combination in SAB provides a prolonged duration of sensory as well as motor block and enhances postoperative analgesia in comparison to fentanyl-ropivacaine combination with a higher degree of sedation.

Keywords: analgesia, clonidine, fentanyl, intrathecal, sedation

\section{Introduction}

Subarachnoid block (SAB) is considered as a gold standard for lower abdominal surgeries because it is safe, effective and provides rapid and reliable anaesthesia by producing intense sensory, motor and sympathetic blockade. ${ }^{1}$ But, a shorter duration of block and reduced

\section{*Correspondence: Kriti Chaudhary}

E mail: kritisms@gmail.com

https://orcid.org/0000-0003-0899-4049

Received: $10 / 10 / 2020$

Accepted: $24 / 03 / 2021$

DOI: http:/doi.org/10.4038/slja.v29i1.8694 postoperative analgesia has led to the need for "adjuvants" to potentiate the analgesic effect of the local anaesthetics (LA). Among all the opioids, fentanyl is most preferred as an adjuvant, due to rapid onset and shorter duration of action with high potency. ${ }^{2}$ Safer non-opioid adjuvants were considered to avoid opioidrelated side effects like nausea, vomiting, respiratory depression, and pruritus. ${ }^{3}$ Clonidine, an $\alpha 2$-receptor agonist, prolongs the action of LA while avoiding opioid-related side effects. ${ }^{4-6}$ Many studies have compared the two drugs, but with varying results, especially concerning the duration of sensory and motor block. Our study aimed to compare clonidine and fentanyl as an adjuvant to isobaric ropivacaine for the duration of analgesia, sensory and motor block characteristics, haemodynamic stability, sedation 
score and any adverse event in the intraoperative and 12-hour postoperative period, in patients undergoing vaginal hysterectomy under SAB.

\section{Subjects and Methods}

This prospective, randomized, double-blind study was conducted at a tertiary care hospital between April 2017 to May 2018. Prior permission from the institutional ethical committee and written consent from all the study subjects was obtained. All the females admitted for elective vaginal hysterectomy were screened for the inclusion criteria of American Society of Anaesthesiologists (ASA) physical status I or II, aged 40 to 65 years, weighing 50 to $80 \mathrm{~kg}$ and height of 150 to $180 \mathrm{~cm}$. Patients having an allergy to local anaesthetics, infection at the puncture site or with a history of medical complications (viz. diabetes, hypertension, coagulation disorder, heart disease, cerebrovascular accidents, endocrine, severe hepatic and renal diseases, neuromuscular disorders) or other contraindications to spinal anaesthesia were excluded from the study.

The sample size was calculated considering a $30 \%$ difference in the duration of sensory block as significant, with an alpha error of 0.05 and power of study $80 \%$. All the 80 eligible patients were randomized into two groups (Group $\mathrm{C}$ and Group F) of 40 each employing a computergenerated randomization program and sealed in an opaque envelope. A person, not involved in the study, received the envelope to prepare the drug. Group C received intrathecal $0.75 \%$ isobaric ropivacaine $(3 \mathrm{ml})$ with $75 \mu \mathrm{g}$ clonidine $(0.5 \mathrm{ml})$ while Group F was given intrathecal $0.75 \%$ isobaric ropivacaine $(3 \mathrm{ml})$ with $25 \mu \mathrm{g}$ fentanyl $(0.5 \mathrm{ml})$ to form a final volume of 3.5 ml. Observer 1, who administered the block. Observer 2, who monitored the perioperative haemodynamics and quality of block, were blinded to the drug preparation.

On arrival in the operating room, intravenous (IV) access was secured with an $18 \mathrm{G}$ or $20 \mathrm{G}$ cannula and preloading was done with Ringer lactate $(10 \mathrm{ml} / \mathrm{kg})$. Standard ASA monitoring was attached to record heart rate (HR), mean blood pressure (MBP), systolic blood pressure (SBP), diastolic blood pressure (DBP) and oxygen saturation $\left(\mathrm{SpO}_{2}\right)$. Under strict aseptic precautions, SAB was performed by $25 \mathrm{G}$ Quincke spinal needle in the midline at L3-L4 level in sitting position. The loaded drug was injected following a free flow of cerebrospinal fluid. The time after injection was considered as the zero time of study and all measurements were recorded from this point.

MBP, SBP, DBP, HR were measured and recorded before \& after intrathecal drug injection (every $5 \mathrm{~min}$ till $30 \mathrm{~min}$ ) and thereafter every 15 min till $150 \mathrm{~min}$ or the end of surgery whichever was later and in the postoperative period every two hourly till 12 hours. Any event of bradycardia (HR was $<50$ beats/min or $<20 \%$ baseline) and hypotension (MBP $<20 \%$ baseline) was noted and treated with IV atropine $0.6 \mathrm{mg}$ and me phentermine $6 \mathrm{mg}$, respectively.

\section{Parameters studied}

The sensory loss was assessed by the pinprick method. ${ }^{7,8}$ Onset of sensory block at T10 level, time to achieve the loss of sensation at highest dermatomal level, sensory block duration (time from the highest level of sensory block achieved to regression to S2 segment) and duration of surgery was noted.

Modified Bromage scale (MBS) was used to establish the motor block. ${ }^{9}$ Onset of motor block (time from injection to achieve MBS 3) and motor block duration (time interval from MBS 3 to regression to MBS 0) was noted.

The sedation score was assessed intraoperatively using the Campbell Sedation Scale. ${ }^{10}$ Quality of sedation was also reviewed every hour until 6 hours post-operatively.

Postoperative pain was evaluated by the Visual Analogue Scale (VAS) of 0 to $10(0=$ no pain, $10=$ severe pain). The time to the request of first rescue analgesia was noted to determine the duration of analgesia. $1 \mathrm{~g}$ IV paracetamol was given on demand to relieve pain.

Any adverse event, for instance, bradycardia, hypotension, excessive sedation, retention of urine or respiratory depression, pruritus and postoperative nausea, vomiting (PONV) were also recorded. At the end of observation period, patient's satisfaction regarding the procedure was assessed using satisfaction score as $(1=$ excellent; 2 = fair; $3=$ good and $4=$ poor ).

In this study, the primary outcome variable was the duration of analgesia. The secondary outcome variables were onset and duration of sensory and motor block, haemodynamic profile, 
sedation and any adverse event. Statistical Packages for Social Sciences (SPSS) version 21 was used to analyse the data. Chi-square test or Fischer's exact test was utilized for the comparison of categorical data. Quantitative data was compared by unpaired student t-test. For statistical significance, a $\mathrm{P}$ value of $<0.05$ was considered.

\section{Results}

Both groups were comparable for their demographic profile and duration of surgery. As shown in Table 1 , there was no statistically significant difference found in the onset of sensory block, the onset of motor block and time to maximum cephalad spread of drug among the two groups. However, the duration of sensory and motor block and duration of analgesia was found to be significantly longer in Group $\mathrm{C}$ as compared to Group $\mathrm{F}$ with a $\mathrm{P}$ value of $<0.001$. Baseline haemodynamic parameters were comparable in the two groups. Intraoperatively, a drop in the mean value of SBP and MBP from 30 to $90 \mathrm{~min}$ and DBP from 30 to $75 \mathrm{~min}$ was found in both the groups (Figure 1). Although this drop was statistically significant in Group C as compared to Group F ( $\mathrm{P}$ value $<0.05$ ), it was not clinically significant as the drop was not more than $20 \%$. During the postoperative period, SBP and DBP during the first 10 hours and MBP during 2-8 hours of the postoperative period were found to be significantly lower in Group $\mathrm{C}$ as compared to that in Group F (P value <0.05). But the overall incidence of hypotension from baseline value was similar in both the groups (Table 2).

\begin{tabular}{|l|c|c|c|}
\hline \multicolumn{4}{|l|}{$\begin{array}{l}\text { Table 1 } \\
\text { Comparison of demographic profile and block characteristics }\end{array}$} \\
\hline Variables & $\begin{array}{c}\text { Group C } \\
\text { Mean } \pm \text { SD) }\end{array}$ & $\begin{array}{c}\text { Group F } \\
\text { (Mean } \pm \text { SD) }\end{array}$ & P value* \\
\hline Age (years) & $50.85 \pm 10.12$ & $54.02 \pm 7.31$ & $0.11^{*}$ \\
\hline Height (cm) & $168.78 \pm 6.29$ & $167.02 \pm 7.35$ & $0.146^{*}$ \\
\hline Weight (kg) & $58.2 \pm 6.5$ & $58.2 \pm 6.5$ & $0.298^{*}$ \\
\hline Duration of surgery (min) & $117.8 \pm 8.3$ & $118.5 \pm 8.7$ & $0.698^{*}$ \\
\hline Onset of sensory block (min) & $5.55 \pm 1.31$ & $5.55 \pm 1.06$ & $0.999^{*}$ \\
\hline Onset of motor block (min) & $11.12 \pm 1.78$ & $11.10 \pm 1.98$ & $0.952^{*}$ \\
\hline Time to achieve highest level (min) & $7.60 \pm 1.87$ & $7.65 \pm 1.56$ & $0.897^{*}$ \\
\hline Duration of sensory block (min) & $363.37 \pm 58.57$ & $214.37 \pm 41.95$ & $<0.001^{*}$ \\
\hline Duration of motor block (min) & $300.37 \pm 48.79$ & $177.75 \pm 33.93$ & $<0.001^{*}$ \\
\hline Duration of analgesia (min) & $476.92 \pm 72.9$ & $298.52 \pm 58.3$ & $<0.001^{*}$ \\
\hline C: Clonidine, F: Fentanyl, SD: Standard deviation, *unpaired t-test & \\
\hline
\end{tabular}

Table 2

Satisfaction score and adverse effects compared between the two groups

\begin{tabular}{|c|c|c|c|}
\hline Variables & Group C (n=40) & Group F (n=40) & P value \\
\hline Satisfaction score & & & \\
Excellent & 20 & 17 & $0.653^{*}$ \\
Good & 12 & 13 & $0.809^{*}$ \\
Fair & 08 & 10 & $0.788^{*}$ \\
\hline Adverse effects & 02 & 02 & $1.0^{*}$ \\
Hypotension & 03 & 00 & $0.24^{*}$ \\
Bradycardia & 03 & 04 & $1.0^{*}$ \\
PONV & 00 & 04 & $0.115^{*}$ \\
Pruritus & & & \\
C: Clonidine, F: Fentanyl, *Chi-square or Fischer's exact test, PONV: Postoperative \\
nausea and vomiting
\end{tabular}


Figure 1

Intraoperative and postoperative trends of haemodynamics compared in the two groups

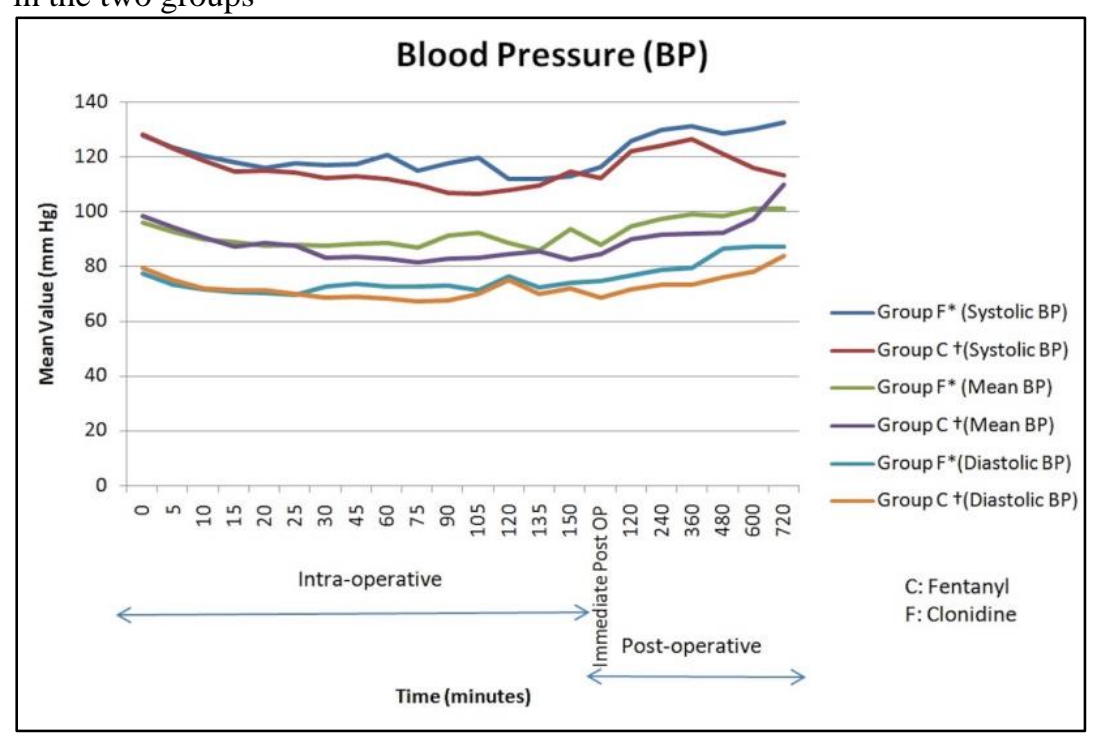

Figure 2

Intraoperative and postoperative sedation score compared among the two groups

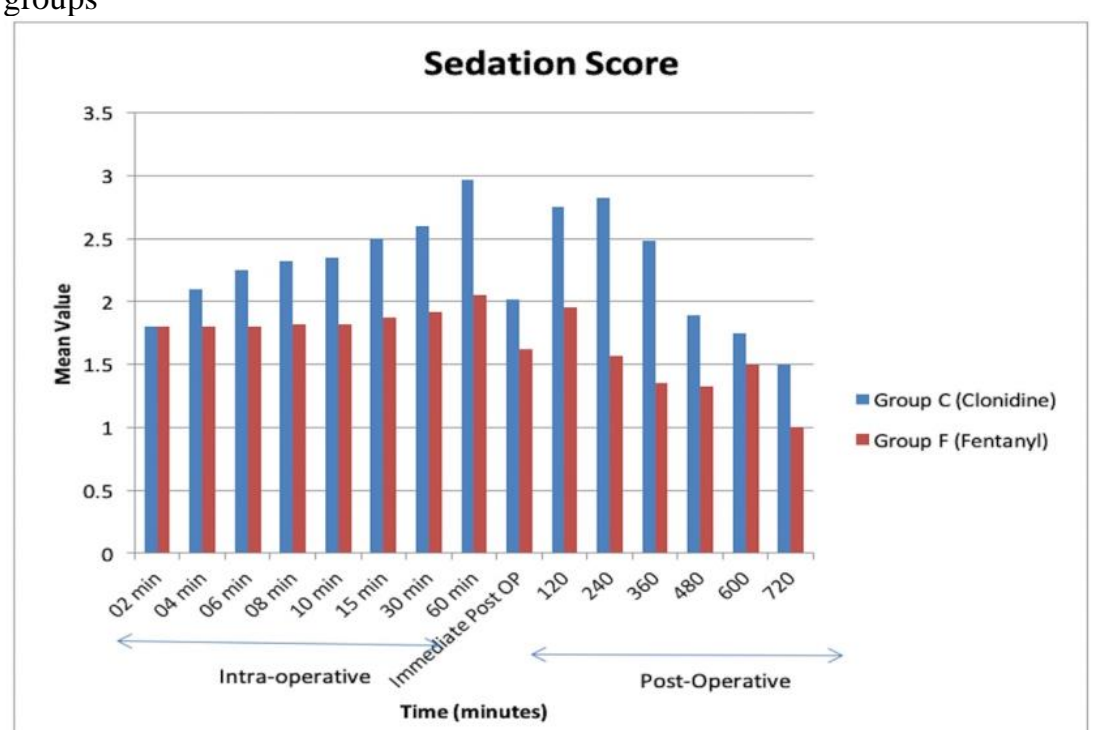

There was a statistically significant difference in terms of Campbell Sedation score in the groups $\mathrm{C}$ and $\mathrm{F}$ intraoperatively and in the postoperative period till 5 hours with more patients being sedated in Group $\mathrm{C}$ as compared to Group $\mathrm{F}$ (Figure 2). There was no statistically significant difference in bradycardia and hypotension among the two groups with a $\mathrm{P}$ value of 1 and 0.24 respectively (Table 2 ). Three patients in the clonidine group and four patients in the fentanyl group complained of PONV $(\mathrm{P}$ value $=1.0)$ and 4 patients in the fentanyl group reported pruritus ( $\mathrm{P}$ value $=0.11$, but it was not statistically significant. Similarly, there was no significant difference between the two groups in terms of satisfaction score (Table 2).

\section{Discussion}

Uncontrolled pain leads to an endocrine, metabolic and inflammatory response which is associated with a delay in the recovery of the patient. Thus, effective pain relief in the patients undergoing a surgical procedure is of utmost importance for early mobilization, decreases pulmonary/cardiac complications, reduces the likelihood of deep vein thrombosis, shortens hospital stay and increases patient satisfaction. Studies have shown that intrathecal opioids can 
enhance the duration of analgesia at subtherapeutic doses of LA and among the lot, fentanyl is the most commonly used opioid adjuvant. ${ }^{2}$ Clonidine prolongs the action of local anaesthetics by inhibiting the transmission of $\mathrm{A} \delta$ and $\mathrm{C}$ nerve fibres and itsanalgesic action is by activating the postsynaptic $\alpha 2$-receptors in the dorsal horn of the spinal cord. ${ }^{11}$ A study concluded that clonidine has an advantage over fentanyl as an adjuvant to ropivacaine in terms of duration of $\mathrm{SAB}$ and postoperative analgesia. ${ }^{12}$ Whereas, another study found that intrathecal fentanyl and clonidine were comparable with respect to the duration of sensory and motor block. ${ }^{13}$ Our study compared the efficacy and safety of intrathecal clonidine and fentanyl as an adjuvant to isobaric ropivacaine for vaginal hysterectomy under SAB in terms of duration of analgesia, haemodynamic profile, onset and duration of sensory and motor block as well as the side effects.

Most studies have used lower doses of clonidine $(15,30$ or $50 \mu \mathrm{g})$, to avoid associated sedation and haemodynamic side effects, while we used a dose of $75 \mu \mathrm{g}$ in our study. ${ }^{10,12,14}$ Clonidine shows a dose-dependent increase in the duration of analgesia. A study compared three different doses of intrathecal clonidine $15 \mu \mathrm{g}, 30 \mu \mathrm{g}$ and $45 \mu \mathrm{g}$ with isobaric ropivacaine for infraumbilical surgeries and concluded that increasing the dose of clonidine increases the quality of SAB with manageable side effects. ${ }^{15}$

Our results showed that the duration of analgesia was comparatively longer in Group C (476.92 \pm $72.98 \mathrm{~min})$ than in Group F $(298.52 \pm 58.30$ min). Similar findings were found by a study comparing clonidine $(50 \mu \mathrm{g})$ and fentanyl when added to intrathecal bupivacaine for intraabdominal surgery. ${ }^{10}$ Whereas, another study found a similar duration of analgesia with intrathecal fentanyl and clonidine added to hyperbaric ropivacaine, which may be due to the low dose of clonidine used by them $(15 \mu \mathrm{g})$ as compared to us. ${ }^{14}$

In our study, the onset of sensory and motor block was similar in both the groups, which is in concordance with the results observed by two other studies. ${ }^{12,16}$ The duration of motor block was significantly longer in Group C (300.37 \pm 48.79 min) as compared to Group F (177.75 \pm
$33.93 \mathrm{~min}$ ) in our study. A similar trend was observed by another study. ${ }^{17}$

Although intraoperative and postoperative changes in SBP, DBP and MBP were significantly lower in Group $\mathrm{C}$ as compared to Group $\mathrm{F}$ at various time points in our study (Figure 1), it was not clinically significant. The overall incidence of hypotension and bradycardia from baseline value was also similar in both the groups in our study. This was in line with a study, which compared fentanyl $(25 \mu \mathrm{g})$, and clonidine $(60 \mu \mathrm{g})$ as an adjuvant to intrathecal $15 \mathrm{mg}$ ropivacaine and found haemodynamic changes in clonidine and fentanyl group although statistically significant but not clinically significant. ${ }^{17}$

Intraoperative and postoperative sedation score was found to be significantly more in Group C than Group F in our study, which was in concordance with another study. ${ }^{10}$ In our study, clonidine as an adjuvant resulted in a lower incidence of PONV and pruritus than when fentanyl was used. However, these findings were not statistically significant among the two groups.

The limitation of our study was that the effect of a higher dose of intrathecal clonidine in geriatric patients and patients with other comorbidities like cardiovascular system cannot be inferred from this study and further research is needed in this respect.

We conclude that intrathecal clonidine is a good alternative to fentanyl when used in conjunction with $0.75 \%$ isobaric ropivacaine for vaginal hysterectomy under SAB. Clonidineropivacaine combination increases the duration of sensory and motor block and provides prolonged postoperative analgesia as compared to fentanyl-ropivacaine combination while avoiding opioid-related side effects. While using adjuvants, haemodynamic parameters need to be closely monitored, even more with clonidine usage. The effect of various dosage combinations of ropivacaine and clonidine on haemodynamic profile needs further research to calibrate the optimum response.

\section{References}

1 Gaiser RR. Should intrathecal lidocaine be used in the 21 st century? J Clin Anesth 2000;12: 476-81. 
https://doi.org/10.1016/s0952-8180(00)00186$\underline{0}$

2 Stamenkovic D, Geric V, Djordjevic M, et al. Subarachnoid morphine, bupivacaine and fentanyl as part of combined spinal epidural analgesia for low anterior resection. A prospective, randomized, double-blind clinical trial. Anaesth Intensive Care 2009; 37: 552-60. https://doi.org/10.1177/0310057x0903700410

3 De Kock M. Site of haemodynamic effects of alpha 2-a drenergic agonists. Anesthesiology 1991; 75: 715-6.

https://doi.org/10.1097/00000542-199110000$\underline{00046}$

4 Benhamou D, Thorin D, Brichant JF, et al. Intrathecal clonidine and fentanyl with hyperbaric bupivacaine improves analgesia during cesarean section. Anesth Analg 1998; 87: 609-13.

https://doi.org/10.1097/00000539-199809000$\underline{00022}$

5 Kothari N, Bogra J, Chaudhary AK. Evaluation of analgesic effects of intrathecal clonidine along with bupivacaine in cesarean section. Saudi J Anaesth 2011; 5: 31-5. https://doi.org/10.4103/1658-354x.76499

Shah B, Shidhaye R, Divekar D, et al. A randomized, double blind, controlled study on the effects of addition of clonidine to bupivacaine used for patients undergoing spinal anaesthesia. Sri Lankan Journal of Anaesthesiology 2011; 19: 17-21.

https://doi.org/10.4038/slja.v19i1.1715

7 Rocco AG, Raymond SA, Murray E, et al. Differential spread of blockade of touch, cold, and pinprick during spinal anaesthesia.

AnesthAnalg. 1985; 64: 917-23.

https://doi.org/10.1213/00000539-198509000$\underline{00011}$

8 Sakura S, Sakaguchi Y, Shinzawa M, et al. The assessment of dermatomal level of surgical anaesthesia after spinal tetracaine. AnesthAnalg 2000; 90: 1406-10.

https://doi.org/10.1097/00000539-200006000$\underline{00027}$

9 Sapate M, Sahu P, Shah B, et al. Evaluation of bupivacaine-clonidine combination for unilateral spinal anesthesia in lower limb below-knee orthopedic surgery. Saudi J Anaesth. 2014; 8: 384-7.

https://doi.org/10.4103/1658-354X.136626

10 Bajwa BS, Singh AP, Rekhi AK. Comparison of intrathecal clonidine and fentanyl in hyperbaric bupivacaine for spinal anaesthesia and postoperative analgesia in patients undergoing lower abdominal surgeries. Saudi J Anaesth 2017; 11: 37-40.

https://doi.org/10.4103/1658-354x.197337
11 Giovannitti Jr JA, Thoms SM, Crawford JJ. Alpha-2 adrenergic receptor agonists: a review of current clinical applications. Anesth Prog 2015; 62: 31-9.

https://doi.org/10.2344/0003-3006-62.1.31

12 Sharan R, Verma R, Dhawan A, Kumar J. Comparison of clonidine and fentanyl as adjuvant to ropivacaine in spinal anaesthesia in lower abdominal surgeries. Anesth Essays Res 2016; 10: 526-31.

https://doi.org/10.4103/0259-1162.180781

13 Mahendru V, Tewari A, Katyal S, et al. A comparison of intrathecal dexmedetomidine, clonidine, and fentanyl as adjuvants to hyperbaric bupivacaine for lower limb surgery: A double blind controlled study. $J$ Anaesthesiol Clin Pharmacol 2013; 29: 496502.

https://doi.org/10.4103/0970-9185.119151

14 Bathari R, Bhalotra AR, Anand R, Kumar V. A randomised trial to compare the effect of addition of clonidine or fentanyl to hyperbaric ropivacaine for spinal anaesthesia for knee arthroscopy. S Afr J AnaesthAnalg 2016; 22: 14-8.

https://doi.org/10.1080/22201181.2015.10896 $\underline{67}$

15 Barsagade W, Tirpude NG, Ratolikar G. Effects of addition of different doses of clonidine to intrathecal ropivacaine in lower limb and subumbilical surgeries. Int Jour of Biomed Res [Internet] 2016 Sep [cited 2020 Apr 22]; 7(9): 689-94. Available from: https://ssjournals.com/index.php/ijbr/article/vi ew/3624

16 Chaudhary A, Bogra J, Singh PK, et al. Efficacy of spinal ropivacaine versus ropivacaine with fentanyl in transurethral resection operations. Saudi J Anaesth 2014; 8: 88-91.

https://doi.org/10.4103/1658-354x.125951

17 Chhabra AR, Jagtap SR, Dawoodi SF. Comparison of clonidine versus fentanyl as an adjuvant to intrathecal ropivacaine for major lower limb surgeries: A randomized doubleblind prospective study. Indian J Pain 2013; 27: $170-4$.

https://doi.org/10.4103/0970-5333.124603 